\title{
The tandemly repeated NTPase (NTPDase) from Neospora caninum is a canonical dense granule protein whose RNA expression, protein secretion and phosphorylation coincides with the tachyzoite egress
}

Iván Pastor-Fernández ${ }^{1}$, Javier Regidor-Cerrillo, Gema Álvarez-García', Virginia Marugán-Hernández , Paula García-Lunar ${ }^{1}$, Andrew Hemphill ${ }^{2}$ and Luis M. Ortega-Mora ${ }^{*}$

\begin{abstract}
Background: NTPases (also NTPDases) are enzymes with apyrase activity. They are widely distributed among eukaryotes, and also among members of the family Sarcocystidae. In Toxoplasma gondii, the TgNTPase accumulates in the dense granules, and has been commonly associated with the strain virulence. In the closely related Neospora caninum, the NcNTPase lacks nucleoside diphosphate hydrolase activity and appears to be more abundant in virulent isolates, indicating that it may contribute to the pathogenicity of neosporosis. However, so far no additional information on NcNTPase has been provided.

Methods: Herein, the NcNTPase coding sequences were analysed by different in silico and de novo sequencing approaches. A comparative analysis of NcNTPase and NcGRA7 in terms of protein dynamics, secretion, phosphorylation, and mRNA expression profiles during the tachyzoite lytic cycle was also carried out. Moreover, NcNTPase immunolocalization was analysed by confocal microscopy techniques over a set number of time-points.

Results: We describe the presence of three different loci containing three copies of the NcNTPase within the Nc-Liv genome, and report the existence of up to four different NcNTPase alleles in Nc-Liv. We also provide evidence for the occurrence of diverse protein species of the NcNTPase by two-dimensional gel electrophoresis. Both NcNTPase and NcGRA7 were similarly up-regulated and secreted during the egress and/or early invasion phases, and were phosphorylated. However, its secretion was not affected by the addition of calcium modulators such as A23187 and ethanol. NcNTPase and NcGRA7 localized in dense granules and parasitophorous vacuole membrane throughout the lytic cycle, although differed in their inmunolocalization during early invasion and egress.

Conclusions: The present study reveals the complexity of the NCNTPase loci in N. caninum. We hypothesize that the expression of different isoforms of the NcNTPase protein could contribute to parasite virulence. Our findings showed regulation of expression, secretion and phosphorylation of NcNTPase suggesting a potential role for progression through the tachyzoites lytic cycle.
\end{abstract}

Keywords: Neospora caninum, Dense granule protein, NTPase, Tachyzoite lytic cycle

\footnotetext{
* Correspondence: luis.ortega@vet.ucm.es

'SALUVET, Animal Health Department, Faculty of Veterinary Sciences,

Complutense University of Madrid, Ciudad Universitaria s/n, 28040 Madrid,

Spain

Full list of author information is available at the end of the article
} 


\section{Background}

Neospora caninum is an apicomplexan cyst-forming parasite that causes abortion in cattle and neuromuscular disorders in canids. Rapidly replicating tachyzoites are responsible for parasite dissemination and harmful effects within the infected host, resulting in vertical transmission and abortion [1]. Host tissue damage occurs as a consequence of the tachyzoite lytic cycle, a tightly regulated process that enables parasite propagation with devastating effects for the infected cells [2, 3]. The lytic cycle has been extensively studied in the closely related parasite Toxoplasma gondii [4, 5], but only scarcerly investigated in $N$. caninum. However, preliminary studies showed that the molecular mechanisms that control this process are highly conserved among T. gondii and N. caninum [6].

Micronemes, rhoptries, and dense granules are secretory organelles exclusively found in apicomplexan parasites. The contents of these organelles are sequentially released during the lytic cycle, and play a crucial role in the host-parasite interactions. Specifically, dense granule proteins (GRA) are secreted into the parasitophorous vacuole (PV) and modify the PV membrane (PVM). The PV acts as a metabolically active compartment designed to favour parasite replication [7, 8]. More than 20 GRA proteins have been reported for $T$. gondii [9], and 15 have been identified in $N$. caninum at protein and transcriptional levels [10-12]. Nevertheless, only a limited number of GRA proteins have been studied in $N$. caninum, despite the fact that some GRA proteins such as TgGRA7, TgGRA15, TgGRA16, TgGRA24, TgGRA25 and TgNTPase I, among others, contribute to virulence in T. gondii [13-17].

The $N$. caninum GRA7 protein was extensively characterized during the last few years $[10,18,19]$, whereas little information is available for the NcNTPase [20]. This protein appears to be more abundant in virulent isolates, suggesting that its function could be related with parasite virulence [21]. Besides, multiple genes coding for NTPase have been identified in both, $N$. caninum and $T$. gondii $[20,22]$. In fact, $T$. gondii tachyzoites express two NTPase isoforms (NTPase 1 and 3, also termed NTPase II and I, respectively) which differ in their enzymatic activities, although TgNTPase 3 (with nucleoside triphosphate hydrolase activity) is restricted to the virulent type I strains $[13,23]$. In previous studies, TgNTPase inhibition by antisense RNA compromised parasite replication, suggesting that NTPase activity is essential for parasite function [24]. Despite previous predictions, in a recent study deletion of the genes encoding either or both of the NTPase enzymes had no effect on growth or virulence in mice of T. gondii [25]. Only nucleoside triphosphate hydrolase activity has been found in tachyzoite extracts of $N$. caninum [20], and whether
NcNTPase contributes to $N$. caninum virulence is still unknown.

We here have gone into detail about NTPase gene organization and present a comparative analysis of NcNTPase and NcGRA7 in terms of protein dynamics, secretion, phosphorylation, and mRNA expression profiles during the tachyzoite lytic cycle. This study increases the limited existing knowledge on these GRA proteins in $N$. caninum, and will serve as reference for future studies intended to establish their functional role during the proliferative phase of $N$. caninum.

\section{Methods}

In silico sequence analysis

All sequence data were obtained from ToxoDB v24 (www.toxodb.org), aligned using the CLUSTAL Omega and MUSCLE tools (www.ebi.ac.uk), and edited using the BioEdit software v7.1.1. BLAST tool from the NCBI website (www.ncbi.nlm.nih.gov/BLAST) was employed to match homologous sequences. Protein families were acquired from Pfam database (pfam.sanger.ac.uk). Promoter region sequences were also analysed with the Regulatory Sequence Analysis Tools (RSAT) for protists (rsat01.biologie.ens.fr/rsat/) [26].

\section{Parasite culture}

The Nc-Liv isolate [27] was propagated in vitro by continuous passage in MARC-145 cell culture using standard procedures [28]. For transmission electron microscopy (TEM), murine epidermal keratinocyte cultures were infected with the Nc-Liv isolate as described earlier [29].

\section{Production of recombinant proteins and polyclonal antibodies}

rNcNTPase and rNcGRA7 proteins were obtained as previously described [30]. Briefly, proteins were cloned in the pET45b(+) expression system (Novagen), expressed in E. coli BL21(DE3) pLysS competent cells (Agilent Technologies) as a (His)6-tagged fusion proteins, and purified using HisTrapHP columns coupled to the ÄKTAprime Plus system (GE Healthcare). All proteins were analysed by one-dimensional SDS-PAGE (1-DE) to check their purity and integrity. Electrophoresed proteins were manually excised from prepared Coomassie-stained gels for peptide mass fingerprinting (PMF) following standard procedures [31].

Polyclonal antibodies (PAbs) against rNcNTPase were raised in two female New Zealand White rabbits as previously described [32]. Polyclonal and monoclonal antibodies (MAbs) against rNcGRA7 were obtained as previously described [10, 19]. Affinity purified antibodies were prepared following standard procedures [19]. 


\section{One-dimensional and two-dimensional gel electrophoresis immunoblot}

The NcNTPase protein was detected on Nc-Liv parasite extracts by $1-\mathrm{DE}$ immunoblot as previously described [32]. PAbs $\alpha-r N c N T P a s e$ were used as primary antibody, whereas goat anti-rabbit IgG antibody conjugated to peroxidase (Sigma-Aldrich) was used as secondary antibody. Both antibodies were diluted at 1:1000. Reactions were developed using 4-chloro-1-naphtol (Bio-Rad) as substrate until signal visualization.

For two-dimensional gel electrophoresis (2-DE) immunoblot Nc-Liv tachyzoites were purified in desalting columns and protein extraction was performed as previously described [33]. Briefly, $2 \times 10^{8}$ frozen tachyzoites were resuspended in $200 \mu \mathrm{l}$ of lysis buffer $(6 \mathrm{M}$ urea [Sigma-Aldrich], $2 \mathrm{M}$ thiourea [Fluka], 4 \% CHAPS [Fluka], $65 \mathrm{mM}$ DTE [Calbiochem], $10 \mathrm{mM}$ Tris- $\mathrm{HCl}$ [Panreac] and $1 \mathrm{mM}$ PMSF [Sigma-Aldrich]), processed by 3 cycles of freezing and thawing and solubilized by the addition of $200 \mu \mathrm{l}$ of rehydratation buffer ( $8 \mathrm{M}$ urea, $2 \mathrm{M}$ thiourea, $2 \%$ CHAPS, $65 \mathrm{mM}$ DTE, and $1 \%$ ampholyte [Bio-Rad]). Insoluble material was removed by centrifugation at $13,000 \mathrm{rpm}$ for $30 \mathrm{~min}$ at $4{ }^{\circ} \mathrm{C}$ and protein concentration of the resulting supernatants were determined by the Bradford method (Bio-Rad) using bovine serum albumin (BSA) as standard. Protein extracts $(100 \mu \mathrm{g})$ were resolved by $2-\mathrm{DE}$ as previously described [33]. Isoelectric focusing (IEF) was performed on $17 \mathrm{~cm}$ ReadyStrip $^{\text {Tм }}$ IPG Strips pH 3-10 NL (Bio-Rad) with a Protean IEF cell system (Bio-Rad). Before the seconddimension separation, proteins on the strips were reduced with $4 \%$ DTE and then alkylated with $5 \%$ iodoacetamide in equilibration buffer (6 M urea, $50 \mathrm{mM}$ Tris- $\mathrm{HCl} \mathrm{pH}$ 6.5, 30 \% glycerol, and $2 \%$ SDS). Seconddimension electrophoresis and immunoblotting was performed as previously described [33]. After 2-DE, gels were transferred at $18{ }^{\circ} \mathrm{C}$ onto PVDF membranes for immunoblotting. The blotted membrane was blocked with TBS-Tween 20 buffer containing $5 \%$ (w/v) dry milk and incubated with the PAb $\alpha-\mathrm{rNcNTPase}$ at a 1:50,000 dilution. Then, the membranes were incubated with a goat anti-rabbit IgG antibody conjugated to peroxidase at a 1:100,000 dilution (Sigma-Aldrich). Blots were exposed for 1-30 $\mathrm{s}$ using the Immobilon Western Chemiluminescent HRP Substrate (Millipore). AGFA CP1000 processor and AGFA films (Curix/RP2 Plus, $18 \times 24 \mathrm{~cm}$ ) were used for image acquisition. Image capturing was performed using the PDQuest ${ }^{\mathrm{TM}}$ (Bio-Rad) program.

\section{Transmission electron microscopy}

TEM experiments were carried out as previously described [31]. Infected keratinocyte cultures were fixed, LRWhite embedded and labeled with affinity-purified rabbit $\alpha$-rNcNTPase at a dilution of 1:2, and goat anti-rabbit conjugated to $10 \mathrm{~nm}$ diameter gold particles diluted at 1:5, both in PBS/0.3 \% BSA (Amersham). After extensive washing in PBS, the grids were air-dried, and then contrasted with uranyle acetate and lead citrate [2]. Specimens were viewed on a Phillips 600 TEM operating at $60 \mathrm{kV}$.

\section{Secretion assays}

Secretion assays were performed as previously described [32]. Briefly, $1 \times 10^{8}$ tachyzoites were suspended in $500 \mu \mathrm{l}$ cold phenol red-free DMEM and stimulated with $10 \mu \mathrm{M}$ A23187 (Sigma-Aldrich), 1 \% ethanol (Merck Chemicals), or $10 \mathrm{mM}$ dithiothreitol (DTT, Calbiochem) for $20 \mathrm{~min}$ at $37^{\circ} \mathrm{C}$. Non-stimulated parasites were suspended in $500 \mu \mathrm{l}$ cold phenol red-free DMEM and kept on ice. Secretory fractions in the supernatants were recovered by centrifugation, filtered and supplemented with phosphatase and protease inhibitor cocktails (Sigma-Aldrich). Pelleted parasites were resuspended in cold PBS, supplemented with phosphatase and protease inhibitor cocktails, and recovered by centrifugation. All samples were stored at $-80{ }^{\circ} \mathrm{C}$ until further analyses.

Pellets were resuspended in $1 \times$ Laemmli sample buffer, and supernatans were dissolved in $5 \times$ Laemmli sample buffer to the same final volume $(600 \mu \mathrm{l})$. In order to estimate protein secretion, equal amounts of secretion supernatants and tachyzoite lysates $\left(20 \mu \mathrm{l} /\right.$ lane $\sim 3 \times 10^{6}$ tachyzoites) were loaded onto 1-DE gels for immunoblot analyses. Detection of NcTUB $\alpha$ in secretion supernatants was employed as tachyzoite lysis indicator, whilst NcMIC2 detection was used as positive control of secretion [34]. PVDF membranes were incubated with $\alpha$ rNcNTPase, $\alpha$-rNcGRA7 and $\alpha$-rNcMIC2 at a dilution of 1:5000, and with $\alpha-\mathrm{TUB} \alpha$ at a 1:10,000 dilution (MAb, Sigma-Aldrich). Goat anti-rabbit IgG and goat anti-mouse IgG antibody conjugated to peroxidase were employed as secondary antibodies at 1:25,000 and 1:80,000 dilution, respectively (Sigma-Aldrich). Reactions were developed by chemiluminiscence as described above.

\section{Protein dynamics throughout the lytic cycle by immunofluorescence}

The localization of NcNTPase and NcGRA7 proteins during the lytic cycle of $N$. caninum tachyzoites from 1 to $56 \mathrm{~h}$ post-infection (hpi) was studied by immunofluorescence following previously described protocols [32]. Ice-cold methanol, $2 \%$ paraformaldehyde in PBS, or $2 \%$ paraformaldehyde- $0.05 \%$ glutaraldehyde in PBS, were used as fixatives for 10 to $30 \mathrm{~min}$. Blocked and permeabilised coverslips were labeled with MAb $\alpha-N c S A G 1$ as a tachyzoite surface marker (1:250 dilution) [35], and subsequently with affinity purified PAbs against rNcNTPase and rNcGRA7 (1:8 dilution). Alexa Fluor 488-conjugated goat anti-mouse IgG and Alexa Fluor 594-conjugated goat 
anti-rabbit IgG (Molecular Probes) were employed as secondary antibodies at a 1:1000 dilution. Nuclei were stained with 4,6-diamidino-2-phenylindole (DAPI) dye and coverslips were mounted on glass slides with ProLong ${ }^{\circ}$ Gold antifade reagent (Molecular Probes) for the microscopic visualization. In addition, in order to co-localise NcGRA7 and NcNTPase proteins, some coverslips were incubated with MAb $\alpha$-NcGRA7 (1:25 dilution) and affinity purified PAb $\alpha$-NcNTPase (1:8 dilution), and then with the Alexa Fluor 594-conjugated goat anti-mouse IgG and Alexa Fluor 488-conjugated goat anti-rabbit IgG at 1:1000 dilution, respectively.

Single $1 \mu \mathrm{m}$ slices of immunofluorescence stainings were captured with a Leica TCS-SPE confocal laserscanning microscope (Leica Microsystems) in the Department of Biochemistry and Molecular Biology IV of the Complutense University (Madrid). Image processing was performed using the LAS AF (Leica Microsystems) and the ImageJ software (NCBI, https://imagej.nih.gov/ij/ https://imagej.nih.gov/ij/ ).

\section{Evaluation of NcNTPase and NcGRA7 mRNA expression levels}

Messenger RNA (mRNA) expression levels during the tachyzoite lytic cycle were determined by real-time reverse transcription PCR following a previously described protocol [32]. Samples were obtained at four representative time points, representing either recent invasion, PV maturation, exponential growth of parasites or tachyzoite egress. For this purpose, MARC-145 cultures were infected with the Nc-Liv isolate and maintained during 6, 24, 48 and $56 \mathrm{~h}$. The effect of induced egress on mRNA expression levels of NcGRA7 and NcNTPase was also studied by treating the cultures at 48 hpi with $10 \mathrm{mM}$ DTT for $45 \mathrm{~min}$. Total RNA was extracted using Maxwell $^{\circ} 16$ LEV simplyRNA Purification Kit and RNA integrity was checked by electrophoresis on agarose gels. Reverse transcription was carried out with the master mix SuperScript ${ }^{\circ}$ VILO $^{\text {max }}$ cDNA Synthesis Kit (Invitrogen) and resulting cDNA was diluted 1:20 and analysed by real-time PCR using the Power $\mathrm{SYBR}^{\circ}$ Green PCR Master Mix (Applied Biosystems) in the ABI 7300 Real Time PCR System (Applied Biosystems). Primers used for amplification of NcNTPase, NcGRA7 and the housekeeping genes NcTubulin alpha (TUB $\alpha)$ and NcSAG1 are shown in Table 1. Plasmids containing DNA targets for real-time PCR were employed as standard curves (pET45b(+)-GRA7, pET45b(+)-NTPase, pGEM-T-NcSAG1, and pGEM-T-NcTUB $\alpha$ ) [32]. A seven-point duplicate standard curve based on 10-fold serial dilutions was included on each run. The $-\Delta \mathrm{Ct}$ values were calculated by subtracting the $\mathrm{Ct}$ value of the normalizer genes from the $\mathrm{Ct}$ value of each sample. Relative fold increases or decreases were assessed by the $2^{-\Delta \Delta \mathrm{Ct}}$ method [36], using the mean expression values at $24 \mathrm{~h}$ post-infection as baseline. Raw RNA samples were included in each batch of amplifications to confirm the absence of $N$. caninum genomic DNA. Data analyses of mRNA expression levels were carried out by Kruskal-Wallis and Dunn's tests using GraphPad Prism v.6.01 software.

\section{Phosphorylation assays}

Phosphorylation assays were performed using $N$. caninum infected MARC-145 cells at 56 hpi [32]. Cell cultures were resuspended in alkaline phosphatasecompatible buffer (100 mM sodium chloride [Panreac], $50 \mathrm{mM}$ Tris- $\mathrm{HCl}$ [Panreac], $10 \mathrm{mM}$ magnesium chloride [Merck Chemicals], $1 \mathrm{mM}$ DTT [Calbiochem], $0.2 \%$ Triton X-100 [Merck Chemicals] and protease inhibitor cocktail [Sigma-Aldrich], pH 7.9) or in phosphatase inhibitor buffer (50 mM HEPES [Sigma-Aldrich], $100 \mathrm{mM}$ sodium fluoride [Sigma-Aldrich], $2 \mathrm{mM}$ sodium orthovanadate [Sigma-Aldrich], $2 \mathrm{mM}$ EDTA [Sigma-Aldrich], $1 \mathrm{mM}$ DTT, $0.2 \%$ Triton X-100 and protease inhibitor cocktail). Extracts were disrupted on ice by bathsonication and vortexed during $45 \mathrm{~min}$. Alkaline phosphatase treatment $\left(20 \mathrm{U} \mathrm{CIP} / 2 \times 10^{7}\right.$ tachyzoites, New England Biolabs) was only applied on extracts resuspended in alkaline phosphatase-compatible buffer for

Table 1 Primers used to amplify NcNTPase, NcGRA7, NcSAG1 and NcTUBa sequences by real time-PCR

\begin{tabular}{|c|c|c|c|c|c|c|c|}
\hline Protein & $\begin{array}{l}\text { ToxoDB } \\
\text { accession } \\
\text { number }\end{array}$ & Primer sequences & Reference & Length & Introns $^{a}$ & Slope ${ }^{b}$ & $\mathrm{R}^{2 b}$ \\
\hline NcNTPase & NCLIV_068400 & $\begin{array}{l}\text { Fw-ATTGACCCCGACAGTATTCG } \\
\text { Rv-ACGCTTGAATCAACAGACCT }\end{array}$ & This study & $\begin{array}{l}129 \mathrm{bp} ; \\
\text { Pos. 283-411 }\end{array}$ & No & -3.54 & 0.998 \\
\hline NcGRA7 & NCLIV_021640 & $\begin{array}{l}\text { Fw-GAACAGCATGAAGGGGACAT } \\
\text { Rv-CACCATCTGTAATGGCATCG }\end{array}$ & This study & $\begin{array}{l}130 \text { bp; } \\
\text { Pos. } 97-226\end{array}$ & No & -3.61 & 0.997 \\
\hline NCSAG1 & NCLIV_033230 & $\begin{array}{l}\text { Fw-CGGTGTCGCAATGTGCTCTT } \\
\text { Rv-ACGGTCGTCCCAGAACAAAC }\end{array}$ & [70] & $\begin{array}{l}150 \mathrm{bp} ; \\
\text { Pos. 504-653 }\end{array}$ & No & -3.24 & 0.997 \\
\hline NcTUBa & NCLIV_058890 & $\begin{array}{l}\text { Fw-GGTAACGCCTGCTGGGAG } \\
\text { Rv-GCTCCAAATCCAAGAAGACGCA }\end{array}$ & [71] & $\begin{array}{l}166 \text { bp; } \\
\text { Pos. } 49-214\end{array}$ & Yes* & -3.24 & 0.994 \\
\hline
\end{tabular}

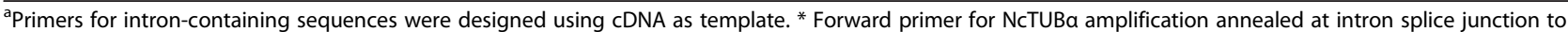
prevent amplification of genomic DNA

${ }^{b}$ Descriptive values of real time-PCR from standard curves for each pair of primers are shown 
90 min at $37^{\circ} \mathrm{C}$. Resulting extracts were stored at $-80{ }^{\circ} \mathrm{C}$ until further analysis.

Tachyzoite extracts were separated by $12.5 \%$ 1-DE supplemented with $25 \mu \mathrm{M}$ Phos-Tag (Wako Pure Chemicals Industries) and $50 \mu \mathrm{M}$ manganese (II) chloride (Merck Chemicals). After electrophoresis, gels were washed once in 0.1 M EDTA in transfer buffer and transferred onto nitrocellulose membranes. Membranes were incubated with $\alpha$-rNcNTPase and $\alpha$-rNcGRA7 PAbs, and then incubated with goat anti-rabbit IgG antibody conjugated to peroxidase. Reactions were developed using 4-chloro-1-naphtol as substrate until signal visualization.

\section{Results}

\section{Molecular characterization of the NcNTPase sequence}

The NcNTPase sequence is currently annotated under the gene ID NCLIV_068400 in the ToxoDB source (chromosome XII [GenBank: FR823393.1], position 6,239,838 to $6,241,718)$. It is classified as an unspecified product and considered as orthologous gene of TgNTPase 1 and 3. The $1881 \mathrm{bp}$ sequence has no introns and codes for a protein of a predicted molecular weight of $\sim 68.7 \mathrm{kDa}$ (Fig. 1a). The predicted protein sequence exhibits a signal peptide of 26 residues, and its EC number is 3.6.1.15 (nucleosidetriphosphate phosphatase). According to the Pfam database, the NcNTPase protein is a member of the GDA1/ CD39 (nucleoside phosphatase) family.

Another gene displaying high similarity with the NcNTPase sequence is NCLIV_068460, a predicted gene on chromosome XII, position $6,285,470$ to $6,290,398$. It codes for an unspecified product which displays 2 introns, with an overall length of $4929 \mathrm{bp}$ and coding for predicted protein of $\sim 109.2 \mathrm{kDa}$. BLAST analyses with NCLIV_068460 sequence showed that this sequence contains the C-terminus of a potential second NcNTPase copy, and the whole nucleotide sequence of an additional copy. In order to clarify the NcNTPase loci distribution, the Nc-Liv chromosome XII was analyzed in detail. In contrast to the information available in ToxoDB, three different loci containing three tandemly repeated copies of the NcNTPase gene were predicted (Fig. 1a). These copies were termed NcNTPase 1 (position 6,239,838 to $6,241,718)$, NcNTPase $2(6,285,037$ to $6,286,918)$ and NcNTPase $3(6,288,517$ to $6,290,398)$ according to their spatial distribution within the genome (Fig. 1a). These analyses concluded that the NCLIV_068460 gene incorporate the last $1449 \mathrm{bp}$ of NcNTPase 2 and $1553 \mathrm{bp}$ of the full length of the NcNTPase 3, and suggest that this gene has been mistakenly predicted (Fig. 1a).

In addition, BLAST searches for the NcNTPase sequence NCLIV_068400 in the NCBI database produced significant alignments for four different mRNA annotations: two obtained from the Nc-Liv mRNAseq data [GeneBank: XM_003886392.1 and XM_003886398.1], and two obtained from the Nc-1 cDNA [GeneBank: AB525222.1 and AB010444.1]. The XM_003886392.1 sequence matched perfectly with the NcNTPase 1 allele (100\% identity), whereas the AB525222.1 and AB010444.1 annotations largely corresponded to the NcNTPase 2 and 3 alleles ( 99 \% identity), respectively (Additional file 1). The XM_003886398.1 annotation matched with the predicted mRNA sequence of the NCLIV_068460 gene.

\section{a}

NcLiv - chromosome XII - FR823393.1

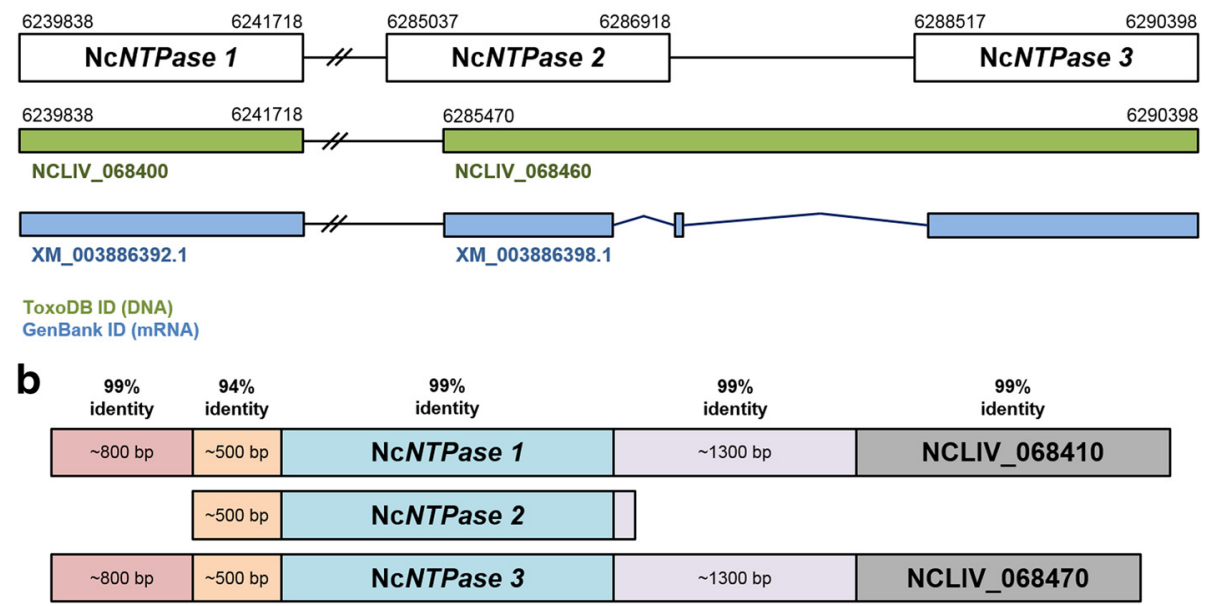

Fig. 1 Diagram of the NCNTPase structure in the Nc-Liv genome based on BLAST analyses. a Schematic alignment of the predicted loci (first row), the annotated genomic sequences (second row), and the annotated transcribed sequences (third row) of the NcNTPase gene. Accession numbers, genomic positions and predicted introns are included on the graphic. b Schematic representation of the NcNTPase 1, 2 and 3 gene structure as predicted in $\mathbf{a}$. Identity scores between $5^{\prime}$ and $3^{\prime}$ flanking regions, and coding sequences are represented on the top of the figure 
Interestingly, the cDNA cloning experiments in this study resulted in the isolation of three additional NcNTPase alleles from Nc-Liv, termed clone 1, 2, and 3 [GenBank: KU513388, KU513389, and KU513390, respectively] (Additional file 1). Hence, at least four different NcNTPase alleles are transcribed in the Nc-Liv (XM_003886392.1, clone 1, clone 2, and clone 3). All new sequences display a high percentage of identity (>99 \%) with the NCLIV_068400 gene (NcNTPase 1), but carry a number of nucleotide changes that match with some of those observed in the NcNTPase 1, 2, and 3 copies (Additional file 1). Clone 1 displayed the highest identity with the NcNTPase 2 and 3 (with 5 nucleotide changes) and clones 2 and 3 with the NcNTPase 2 (with 1 and 2 nucleotide changes, respectively) (Additional file 1 ). In this study, clone 3 was expressed in E. coli and the resulting recombinant protein was used to raise polyclonal antibodies in rabbits.

In order to gain more information on the NcNTPase loci distribution within the Nc-Liv genome, the flanking regions of the NcNTPase 1, 2 and 3 copies were also analysed in detail by BLAST. As shown in Fig. 1b, NcNTPase 1 and 3 share almost perfectly identical upand down-stream sequences. In contrast, these elements were absent in the NcNTPase 2 gene. In order to confirm these findings, specific primers were designed to amplify the up-stream sequences of the NcNTPase 1, 2 and 3. Subsequently, the amplicons were sequenced and analyzed in detail (Additional file 2). Fragments comprising 1331, 536 and 1285 bp were obtained in two directions from the NcNTPase 1, 2 and 3 up-stream regions, respectively. All the sequences were identical to the originally published ones and confirmed the upper distribution of the NcNTPase 1, 2 and 3 copies (data not shown). RSAT analyses on upstream regions confirmed the presence of cis-regulatory motifs (TGAGACGC) within the up-stream regions. Specifically, three of these elements were found for the NcNTPase 1 and 2 copies, and four were found for the NcNTPase 3 (Additional file 2).

According to the Nc-Liv chromosome XII sequence, the NcNTPase 2 and 3 copies contain an additional nucleotide (1882 instead of 1881). This is due to the insertion of an additional $G$, at the position number 8 , in a region with tandemly repeated Gs. Strikingly, this insertion alters the reading frame for the mRNA transcription. However, we confirmed the presence of this additional nucleotide by sequencing analyses of the upstream region on genomic DNA (Additional file 2).

\section{Characterization of NcNTPase protein}

The identity of the recombinant NcNTPase - clone 3 expressed in $E$. coli was corroborated by mass spectrometry (theoretical molecular weight: 69,9 kDa, Score: 214; mass values matched: 25/65; sequence coverage: $47 \%$ ).
Hence, the recombinant protein was employed to develop specific polyclonal antibodies (PAbs).

Immunoblotting of Nc-Liv extracts separated by 1-DE under reducing conditions revealed that the polyclonal $\alpha$-rNcNTPase antiserum reacted with a main band of approximately $64 \mathrm{kDa}$ (Fig. 2a). On immunoblots of NcLiv extracts separated by 2-DE, the polyclonal $\alpha$ rNcNTPase antiserum recognized a chain of at least 5 spots located in the acidic range of the $\mathrm{pH}$ gradient with an approximate $\mathrm{Mr}$ of $60-70 \mathrm{kDa}$ but different isoelectric points (protein species) (Fig. 2b). These findings suggest either the presence of multiple isoforms of the NcNTPase, or the occurrence of protein modifications such as phosphorylation. The same affinity purified antiserum was employed for immunogold TEM, which showed that the NcNTPase protein is clearly associated with the tachyzoites dense granules (Fig. 2c).

\section{Comparative analysis of NcGRA7 and NcNTPase mRNA expression levels during the lytic cycle}

NcNTPase and NcGRA7 transcripts were quantified at different time-points, namely shortly after invasion (6 hpi), PV maturation (24 hpi), exponential growth of parasites (48 hpi) and tachyzoite egress (56 hpi), using NcTUB $\alpha$ as normalizer gene. Both dense granule genes displayed a similar mRNA transcription pattern during the lytic cycle (Fig. 3a), showing the lowest mRNA levels at $24 \mathrm{hpi}$ and the highest at 6 and $56 \mathrm{hpi}$ [Kruskal-Wallis test, $H=29.95, P<0.0001$ for NcNTPase and $H=$ 31.06, $P<0.0001$ for NcGRA7, followed by Dunn's test, $P<0.0001$ (6 hpi vs $24 \mathrm{hpi}$ ) and $P=0.0012$ (56 hpi vs 24 hpi) for NcNTPase and $P<0.0001$ (6 hpi vs 24 hpi) and $P=0.0002$ (56 hpi vs $24 \mathrm{hpi}$ ) for NcGRA7]. Significant differences in mRNA levels were also observed at $48 \mathrm{hpi}$ for both proteins [Dunn's test, $P=0.0025$ (6 hpi vs 48 hpi) for NcNTPase and $P=0.0147$ (6 hpi vs $48 \mathrm{hpi}$ ) for NcGRA7]. Consequently, mRNA levels at 24 hpi were used as baseline to calculate transcript fold increases. NcGRA7 displayed a 3-fold increase in mRNA levels at 6 and 56 hpi. Similarly, NcNTPase showed a 5-fold and a 4fold increase at $6 \mathrm{hpi}$ and $56 \mathrm{hpi}$, respectively. Both genes displayed a 2-fold increase at $48 \mathrm{hpi}$. Results were similar when NcSAG1 was used as a normalizer gene (data not shown).

NcNTPase and NcGRA7 mRNA levels were also assessed after DTT stimulation, which leads to tachyzoite egress. Upon DTT treatment, tachyzoites exhibited significant increases in mRNA levels for both genes [Kruskal-Wallis test, $H=19.18, P<0.0001$ for NcNTPase and $H=15.85, P<0.0001$ for NcGRA7, followed by Dunn's test, $P<0.0001$ (48 hpi vs 48 hpi +DTT) for NcNTPase and $P=0.0038$ (48 hpi vs $48 \mathrm{hpi}+\mathrm{DTT}$ ) for NcGRA7] (Fig. 3b). Similarly to naturally occurring egress, NcGRA7 mRNA levels were 3-fold increased, 

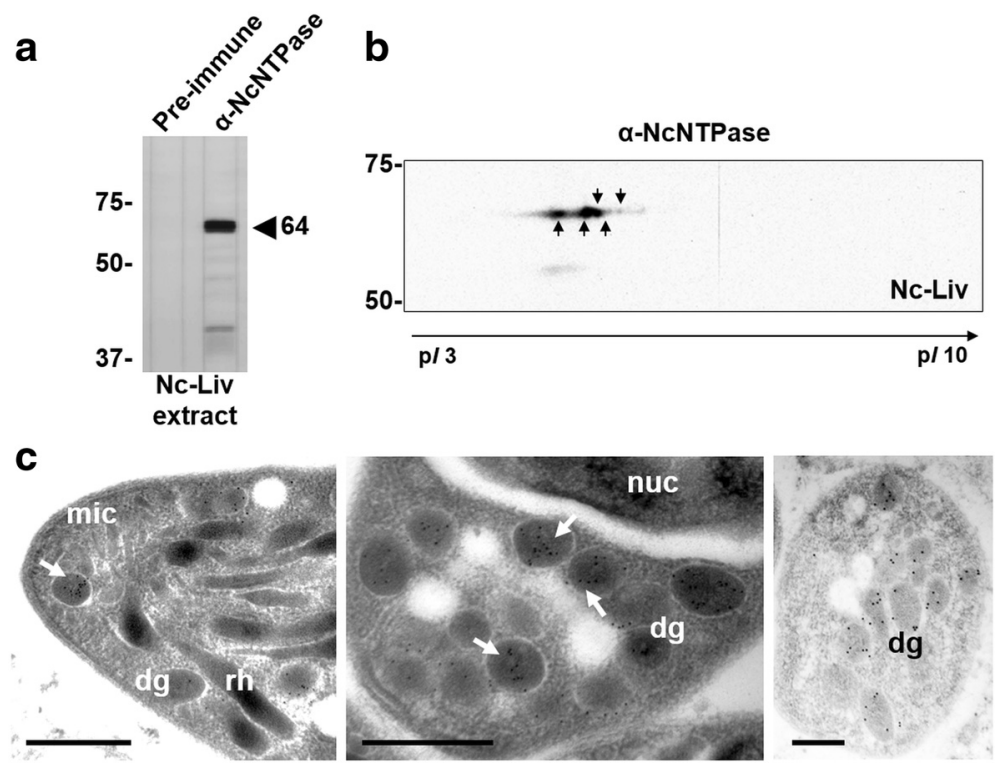

Fig. 2 a N. caninum-based immunoblot showing the immuno-reactivity of a-rNcNTPase antibodies against parasite extracts. A main band of approximately $64 \mathrm{kDa}$ was detected. b NcNTPase-immunome profile of the tachyzoite stage of the Nc-Liv isolate. Proteins were separated along a non-linear pH gradient (pH 3-10 NL, IPG strips; $17 \mathrm{~cm}$ ) in the first dimension and on a $10 \%$ polyacrylamide gel in the second dimension. Following transfer to PVDF membranes, a polyclonal rabbit antiserum raised against rNcNTPase was used. The 2-DE immunoblot was analyzed with the PD-Quest software. Arrows indicate the detected protein spots. c Immunogold TEM of $\mathrm{N}$. caninum tachyzoites labelled with the a-rNcNTPase antibody. The images show in detail the apical region and the dense granules in longitudinal and cross sections. The NcNTPase is clearly associated with dense granules (arrow). Dense granules (dg), micronemes (mic), rhoptries (rh) and the nucleus (nuc) are indicated on the micrographs. Scale-bars: $0.5 \mu \mathrm{m}$

while those coding for NcNTPase displayed a 6-fold increase.

\section{Immunolocalization dynamics of NcGRA7 and NcNTPase throughout the lytic cycle}

Herein, three different fixatives were employed in order to obtain a concise picture of the localization of these two dense granule proteins throughout the lytic cycle. In general, methanol fixation retained more efficiently the reservoirs of intracellular NcNTPase and NcGRA7, whilst paraformaldehyde and glutaraldehyde fixation further preserved the protein after secretion.

Immunofluorescence staining using $\alpha$-NcNTPase antibodies confirmed that NcNTPase is distributed throughout the tachyzoites cytoplasm exhibiting a punctate staining pattern that is reminiscent for dense granules (Fig. 4). NcNTPase secretion was clearly observed in most of the analyzed time points, and could be detected during early invasion, PV maturation, and egress. In addition, the NcNTPase localized to the PVM as soon as the PV was formed. This was particularly visible in samples fixed in the presence of paraformaldehyde and glutaraldehyde (Fig. 4). Compared to NcNTPase, the recognition pattern of $\alpha$-NcGRA7 antibodies observed by immunofluorescence was less distinctive. Protein secretion was also evident during the early invasion, PV maturation and egress, and PVM association was observed (Fig. 5a).
On the other hand, co-immunolocalization studies revealed differences in the distribution pattern of the NcNTPase and NcGRA7 proteins during invasion $(1 \mathrm{~h})$ and egress $(56 \mathrm{~h})$. At these time points, NcNTPase was scattered throughout the entire tachyzoite cytoplasm, whereas NcGRA7 labeling was restricted to more specific areas close to the parasite surface. By contrast, during PV maturation (24 h), NcNTPase and NcGRA7 colocalized much more closely (Fig. 5b).

\section{Effects of calcium on NcNTPase and NcGRA7 secretion}

Freshly purified tachyzoites were incubated in culture medium at $4^{\circ} \mathrm{C}$, and in the presence of A23187, ethanol, and DTT (an egress inducer that activates NcNTPase in vitro) at $37{ }^{\circ} \mathrm{C}$. Immunoblot analyses revealed that NcNTPase and NcGRA7 release was not apparently influenced by any chemical treatment. Both proteins were present in all secreted fractions of both treated and non-treated parasites (Fig. 6). Calciummediated protein secretion was validated by NcMIC2 secretion upon A23187, ethanol or DTT treatment, and tachyzoite lysis was discarded by the lack of detection of NcTUB $\alpha$ in all culture supernatant fractions (Fig. 6).

\section{Phosphorylation of NcNTPase and NcGRA7}

Phosphorylation of NcNTPase and NcGRA7 was studied at $56 \mathrm{hpi}$ to determine whether these proteins are likely 


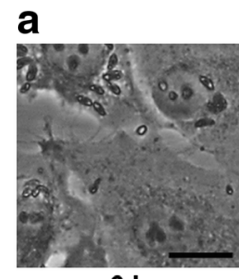

$6 \mathrm{~h}$

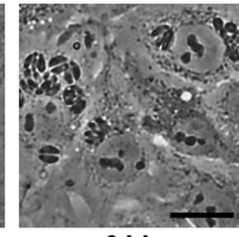

$24 \mathrm{~h}$

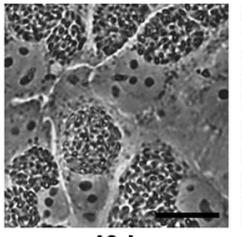

$48 \mathrm{~h}$

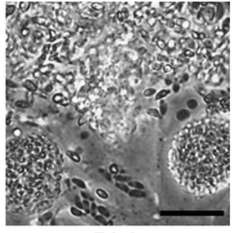

$56 \mathrm{~h}$

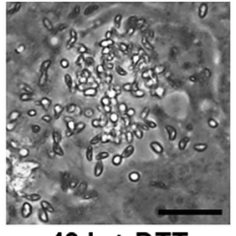

48 h + DTT
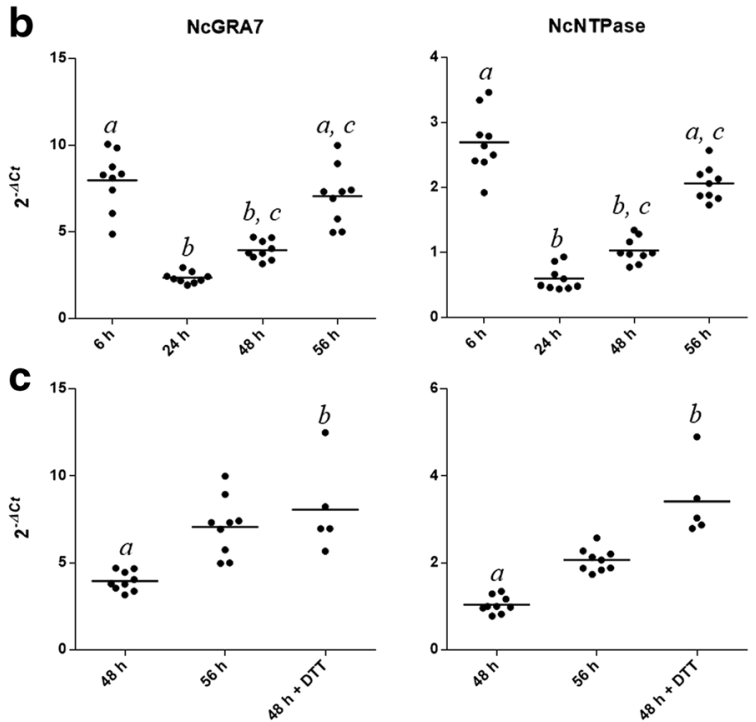

Fig. 3 mRNA levels of NcGRA7 and NcNTPase. Real time-PCR was employed to quantify the mRNA transcription of both proteins along the lytic cycle. a Photomicrographs showing the infection dynamics of the Nc-Liv isolate on MARC-145 cultures at recent invasion (6 hpi), PV maturation (24 hpi), exponential growth of parasites (48 hpi) and tachyzoite egress (56 hpi and 48 hpi + DTT). Scale-bars: 20 um. b mRNA levels of NcGRA7 and NcNTPase during the lytic cycle. c Effect of DTT supplementation to artificially induce egress at $48 \mathrm{hpi}$ on mRNA levels for both proteins. For $\mathbf{a}$ and $\mathbf{b}$, each point represents a single sample and bars represent the mean value. $a, b$ and $c$ indicate significant differences (Kruskal-Wallis test, followed by Dunn's test)

to experience this post-translational modification. For this purpose, tachyzoite extracts were processed under conditions that preserve the phosphorylation status of each protein and resolved by Phos-Tag 1-DE. Both NcNTPase and NcGRA7 showed an electrophoretic mobility shift in those extracts treated with phosphatase inhibitors, which suggests that both proteins are phosphorylated at 56 hpi (Fig. 7) This is in contrast with our previous findings, in which the NcROP40 protein was not phosphorylated under the same conditions [32].

\section{Discussion}

In the present work we have performed, for the first time, a comprehensive study on the localization dynamics, secretion, phosphorylation, and mRNA expression profiles of the two GRA proteins NcNTPase and NcGRA7 throughout the tachyzoites lytic cycle. Although the previously characterized NcGRA7 was included in this study mainly for comparative purposes, we present some new and undescribed aspects of this GRA protein. Moreover, we propose a new model for the NcNTPase genomic distribution supported by different approaches.

In N. caninum the NcNTPase protein has been shown to be more abundant in virulent isolates [21]. However, several functional aspects of this protein still need to be elucidated. Overall, NTPases (also named as NTPDases in the literature) are found in almost all eukaryotes. These enzymes present apyrase conserved regions to hydrolyze nucleoside triphosphates and diphosphates in the presence of divalent cations [37]. The NTPases are also present in both $T$. gondii and Sarcocystis neurona [13, 20, 38]. Intriguingly, orthologues of NTPase are not found in Eimeria and Plasmodium parasites, indicating that this protein may participate in some conserved processes among the Sarcocystidae family members [20,38]. In T. gondii, some NTPase isoforms are restricted to the virulent strains [13]. Nevertheless, there is no consensus regarding their specific function, although it has been proposed they participate in purine salvage to supply energy [39], to be involved in tachyzoite intracellular proliferation and egress $[24,40]$, and in the suppression of 


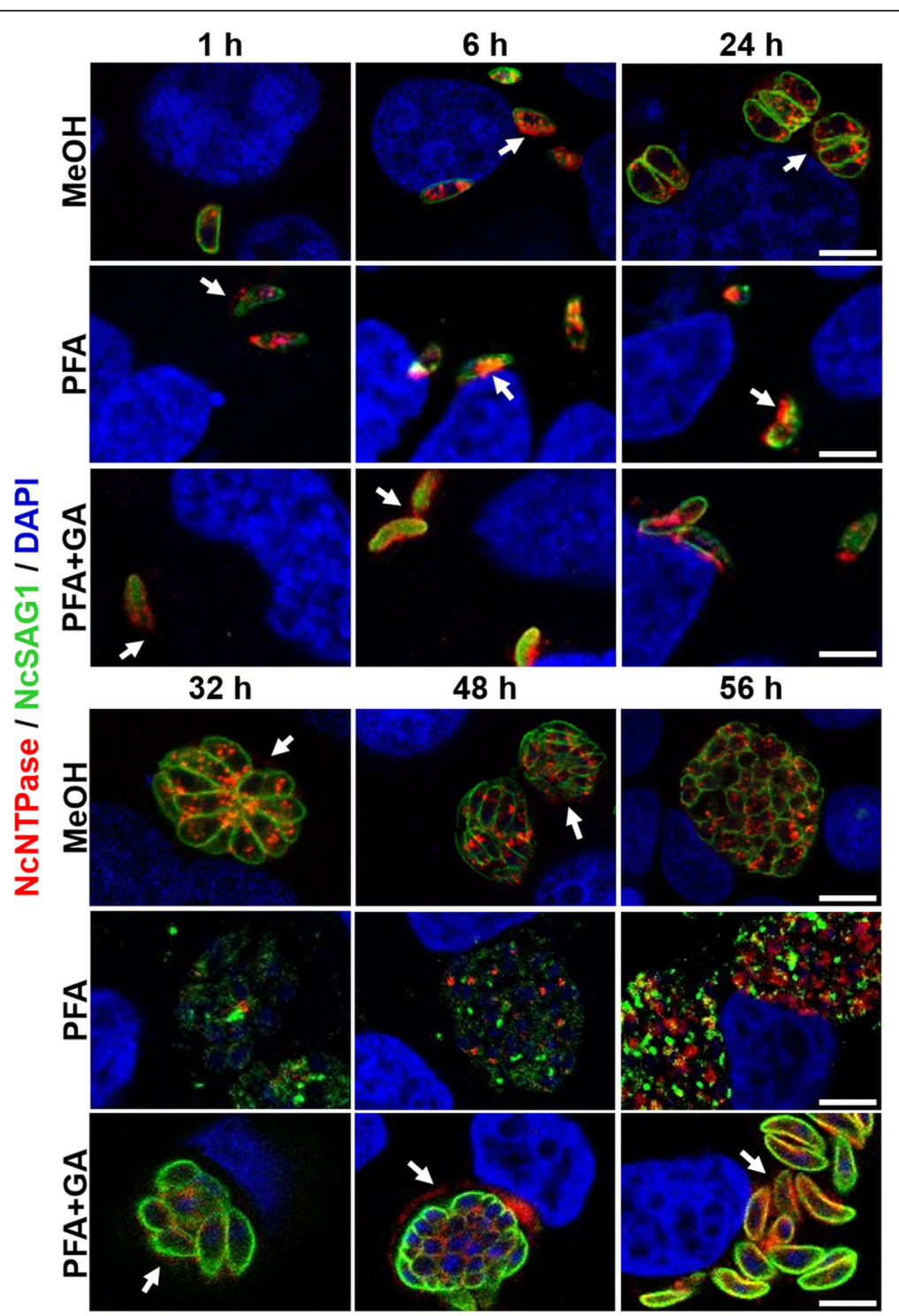

Fig. 4 Confocal laser scanning microscopy of NcNTPase along the lytic cycle of tachyzoites. Infected cultures were fixed with methanol (MeOH), paraformaldehyde (PFA) and paraformaldehyde combined with glutaraldehyde (PFA+GA). Then, coverslips were double labelled with affinity purified antibodies against NcNTPase (red) and monoclonal antibodies against NcSAG1 (green). Nuclei were stained with DAPI (blue). All the images show a single $1 \mu \mathrm{m}$ slice. Scale-bars: $4 \mu \mathrm{m}$

the host immune responses by interfering in purinergic signaling [37, 41-43]. Previous studies suggested that TgNTPase I was refractory to deletion, but in a new study each of the NTPase genes were easily deleted, as well as the double mutant was generated, showing that NTPase I and II were not essential for tachyzoite growth in vitro or virulence in mice. Nevertheless these findings do not rule out another role in different life cycle stages or different hosts [25], and also, the potential relevance of NTPase activity in N. caninum.

Herein, we describe the presence of three different loci for the NcNTPase gene within the Nc-Liv genome. Our sequence analyses showed that NcNTPase 2 lacks the up and down-stream elements shared by NcNTPase 1 and 3. Similarly, T. gondii only expresses the TgNTPase 1 and 3 , which is under the control of an active promoter solely present in those alleles [13, 44]. This is indicative of a similar promoter structure for the NcNTPase alleles. However, our analysis indicates a low percentage of identity between the promoter sequences of the NcNTPase and TgNTPase genes $(<50 \%$; data not shown). In addition, we have predicted the presence of several up-stream cis-acting elements (TGAGACGC). These motifs have shown to be essential for the transcription initiation of certain proteins from the surface and dense granules of $T$. gondii and S. neurona [45-47], 


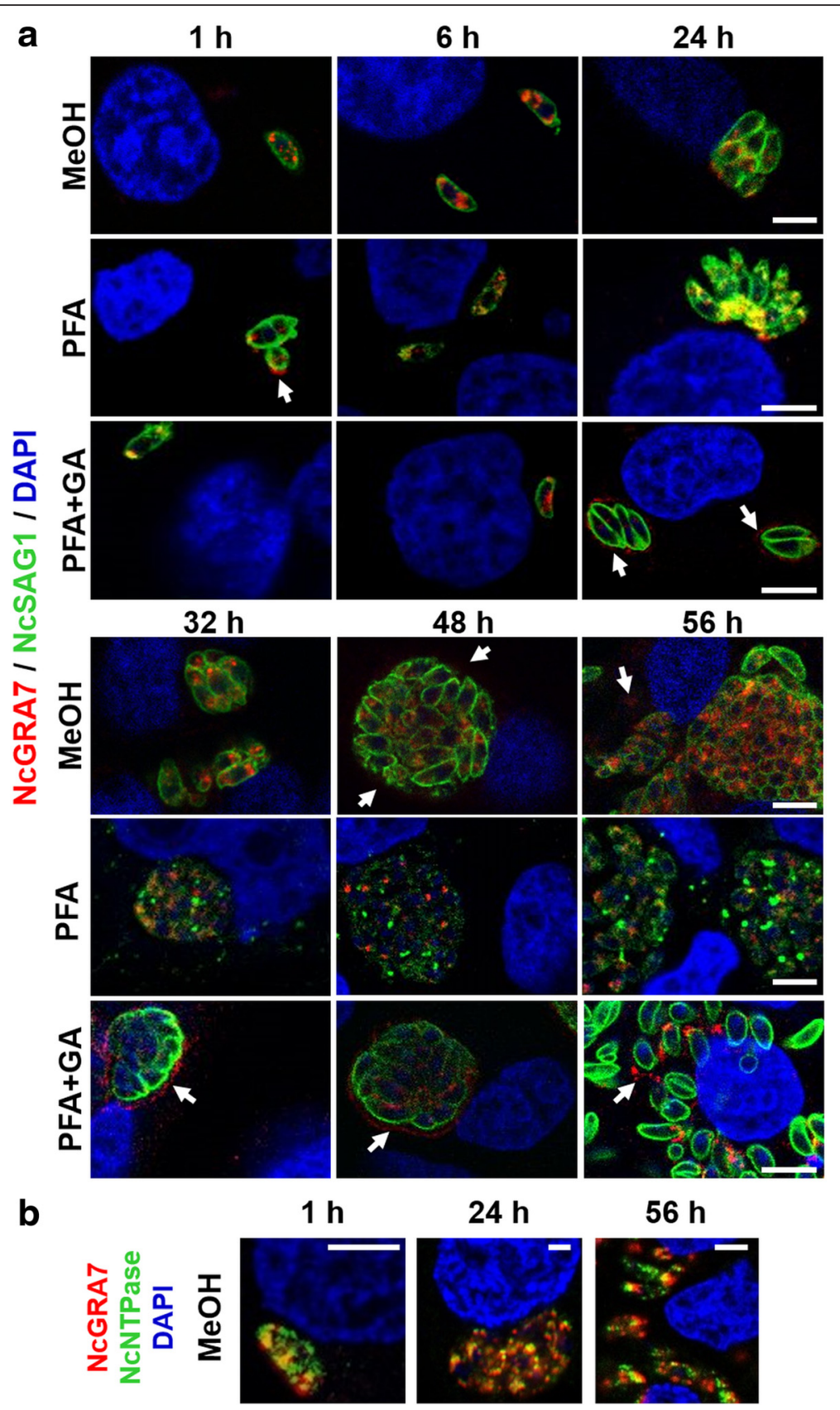

Fig. 5 a Confocal laser scanning microscopy of NcGRA7 along the lytic cycle of tachyzoites. Infected cultures were fixed with methanol (MeOH), paraformaldehyde (PFA) and paraformaldehyde combined with glutaraldehyde (PFA+GA). Then, coverslips were double labelled with affinity purified antibodies against NcGRA7 (red) and monoclonal antibodies against NcSAG1 (green). Nuclei were stained with DAPI (blue). b Confocal laser scanning microscopy of NcNTPase (green) and NcGRA7 (red) along the lytic cycle of tachyzoites. Methanol-fixed cultures were double labelled with affinity purified antibodies against NcNTPase (green) and monoclonal antibodies against NcGRA7 (red). Images taken at 1 hpi, 24 hpi and 56 hpi show a single tachyzoite, a parasitophorous vacuole and a large group of tachyzoites undergoing egress, respectively. Nuclei were also stained with DAPI (blue). All the images show a single $1 \mu \mathrm{m}$ slice. Scale-bars: $4 \mu \mathrm{m}$

and thus, their distribution may be relevant to regulate the transcription process. Nevertheless, promoter mapping by $5^{\prime}$ deletion analysis would be necessary to establish the role of these sequences in the transcription of NcNTPases.
Moreover, we have identified up to four different NcNTPase alleles in the Nc-Liv isolate. Previous studies reported on the presence of three tandemly repeated copies of the TgNTPase gene in T. gondii [22], and Asai and colleagues then also detected up to three different 


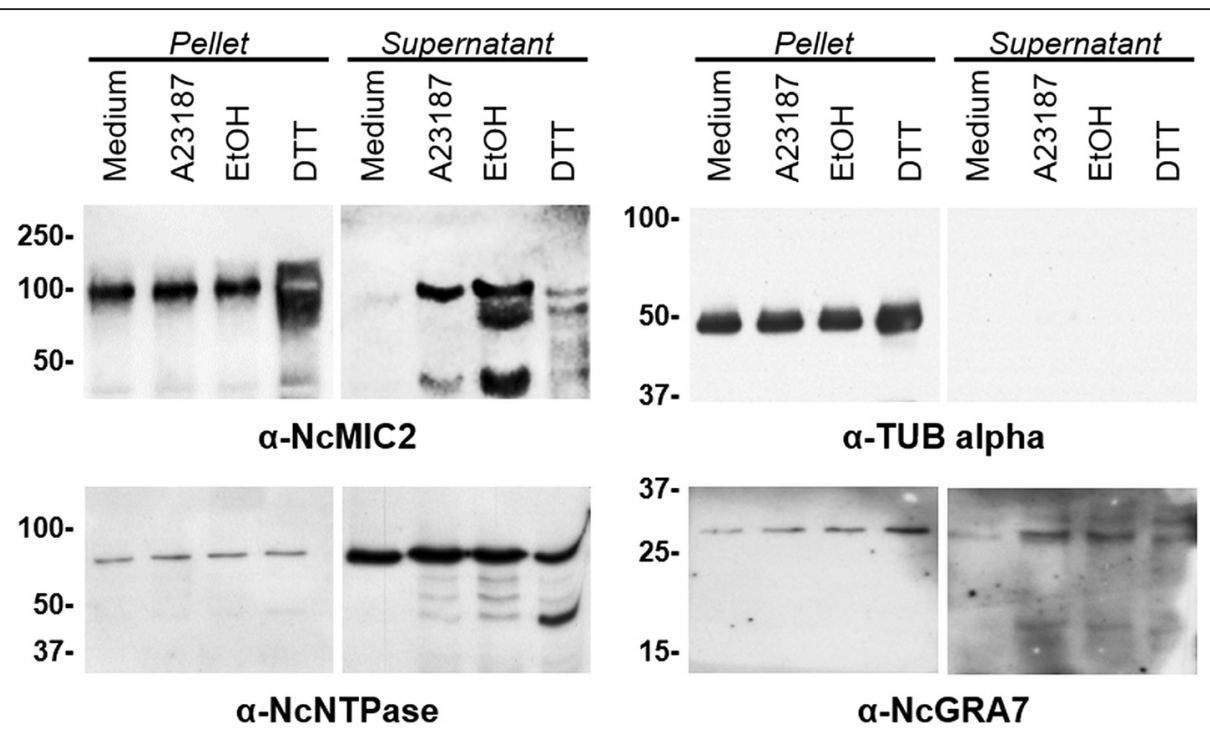

Fig. 6 Effect of culture media $\left(4^{\circ} \mathrm{C}\right), \mathrm{A} 23187\left(37^{\circ} \mathrm{C}\right)$, ethanol $\left(37^{\circ} \mathrm{C}\right)$, and $\mathrm{DTT}\left(37^{\circ} \mathrm{C}\right)$ on secretion of NCNTPase and NcGRA7 proteins as shown by Western-blot using respective antibodies. The same protein samples were also probed by immunoblot analyses with a-NCMIC2 and a-TUBa antibodies to confirm induced secretion and exclude inadvertent tachyzoite lysis, respectively. NcNTPase and NcGRA7 discharge was observed in culture supernatants regardless of the treatment. In contrast, NCMIC2 secretion was only evident after A23187, ethanol and DTT supplementation. Tachyzoite lysis was not detected. All the antibodies specifically reacted against their respective protein on tachyzoite extracts

loci and different alleles of the NcNTPase in N. caninum [20]. However, the NcNTPase 2 and 3 copies show a reading frame shift caused by a single-nucleotide insertion, and thus, it is unlikely that both genes are properly translated. Remarkably, it has been recently described

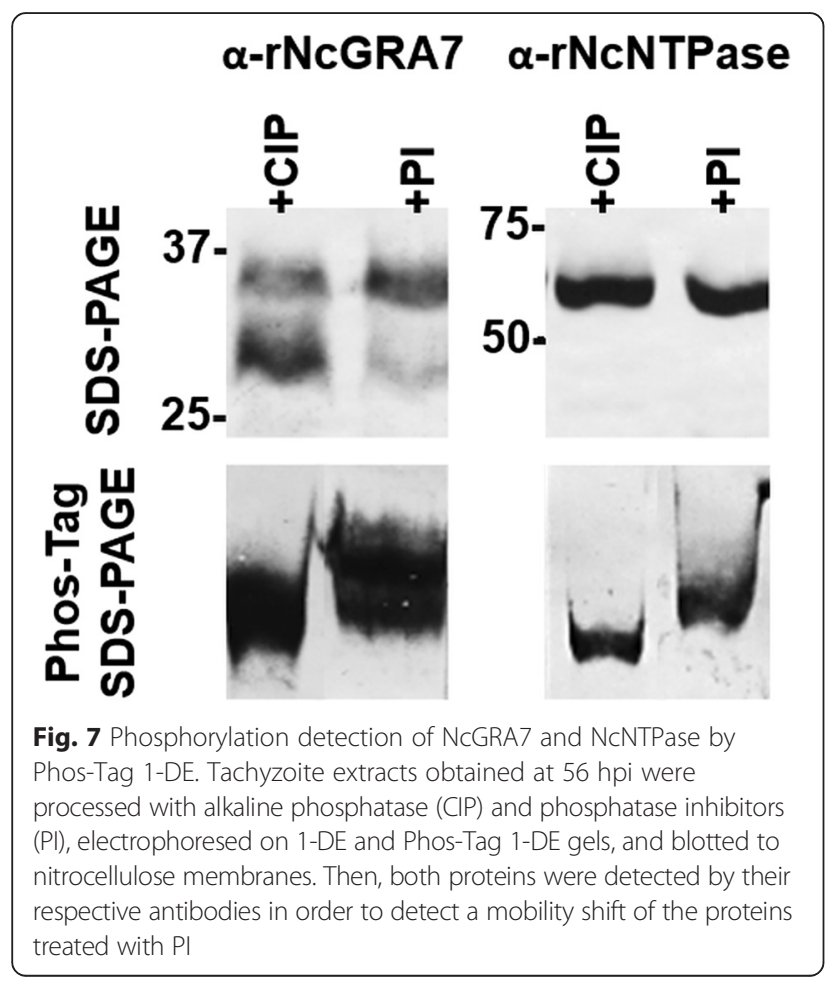

that gene duplications are notoriously underestimated due to collapsing of the assembly in regions containing tandemly duplicated clusters of similar genes [48]. More specifically, Adomako-Ankomah and colleagues have evidenced the existence of expanded loci carrying a variable number of alleles coding for the TgNTPase protein, the numbers of which depend on the isolate. Similarly, several recognized virulent factors of $T$. gondii are clonally expanded and differ in copy number and sequences among isolates [48]. These findings support our evidence on the wide variety of transcribed NcNTPase alleles that we have observed, which could be harboured within the NcNTPase 1 loci. Consistent with this, we failed to amplify the whole NcNTPase 1 gene (coding sequence and flaking regions) by $\mathrm{PCR}$, even when employing specific longrange PCR methods (data not shown). These findings suggest that the NcNTPase allele repertoire may vary among $N$. caninum isolates, and if so, the availability of different genome annotations from diverse $N$. caninum isolates would be highly desirable. However, to date only the NcLiv genome has been fully sequenced [12].

In addition, we have demonstrated the presence of diverse protein species of the NcNTPase in the Nc-Liv isolate by 2-DE immunoblot. This is in accordance with previous proteomic studies in which the NcNTPase protein was detected in different protein spots $[21,49,50]$. Both the presence of multiple NcNTPase alleles, and the detection of different protein species, suggest that $N$. caninum expresses different isoforms of the protein as reported earlier for $T$. gondii [51]. According to this, further studies should be 
carried out in order to clarify the impact of the NcNTPase polymorphism on parasite pathogenicity.

By immunogold TEM, the NcNTPase was localized to the dense granules of intracellular tachyzoites employing a specific $\alpha$-NcNTPase antibody. These findings are in accordance with a previous study in which a similar pattern was observed when extracellular tachyzoites were labelled with an $\alpha$-TgNTPase antibody [20]. In addition, we performed a detailed immunofluorescent tracing of the NcNTPase and NcGRA7 proteins throughout the lytic cycle by using three different fixation protocols. NcNTPase and NcGRA7 secretion was easily detected during early invasion, PV maturation, and egress no matter which fixation was employed. Besides, both proteins associated with the vacuole periphery, indicating that they might interact with the PVM, as previously reported for TgNTPase [22] and the NcGRA7 proteins [10]. Moreover, as shown by the co-localisation studies, the temporal distribution of the NcNTPase and NcGRA7 proteins was distinct during invasion and egress, suggestive of differential protein trafficking at these stages of the lytic cycle. However, NcNTPase is clearly a canonical GRA protein according to earlier described criteria [9]: it has a relatively low molecular weight, the protein carries a $\mathrm{N}$-terminal signal peptide, it colocalized with NcGRA7 within the dense granules, was secreted into the tachyzoite PV, and, similar to NcGRA7, remained there until parasites underwent egress. The possible existence of distinct secretory granules has been recently suggested for the 'canonical' GRA of dense granule and other "GRA" proteins located in uncharacterized cytoplasmic vesicles [9]. If NcNTPase tracking involves different dense granule subpopulations throughout the lytic cycle should be broadly investigated.

The expression of NcNTPase and NcGRA7 transcripts was quantified in infected MARC-145 throughout the lytic cycle. For both, the highest mRNA levels were detected at 6 and $56 \mathrm{hpi}$, coinciding with egress and/or early invasion. Therefore, NcNTPase and NcGRA7 function may be necessary to guarantee the lytic cycle progression. A similar expression pattern was described previously for the rhoptry proteins NcROP40 and NcROP2Fam-1 [32], highlighting the relevance of rhoptry and dense granule proteins for the invasion and/or the immediately following processes in $N$. caninum. This is also in accordance with previous studies carried out with Plasmodium falciparum and T. gondii, that showed that the changes in mRNA levels at specific points of the lytic cycle have a strong influence on the parasite's developmental transitions $[52,53]$. In line with this, a modal switch from expression of proteins involved in invasion and motility of $T$. gondii has been also described in egressed tachyzoites [54, 55].

On the other hand, we quantified the NcNTPase and NcGRA7 mRNA levels after inducing $N$. caninum egress in vitro by DTT treatment $[32,56]$. Significant increases in their mRNA levels were observed after DTT supplementation, suggesting that both proteins may be relevant during the egress or subsequent phases. Similar findings have been reported earlier for the NcROP2Fam-1 protein, whilst NcROP4O mRNA expression was not affected by DTT supplementation [32]. Interestingly, $T$. gondii secretes the reducing agent glutaredoxin as replication increases. In fact, this compound is able to activate the TgNTPase in vitro. Similarly, DTT has been also shown to activate the TgNTPase protein in vitro and to trigger egress of tachyzoites [57, 58]. Although the processes governing egress are not fully understood, intracellular calcium levels appear to trigger the abrupt exit of parasites from the PV, which is accompanied by a rapid decrease in host cell ATP mediated by TgNTPase activation [59]. Hence, we hypothesize that egress regulation in $N$. caninum relies on NcNTPase activation, which is accompanied by an increase in the expression of secreted effectors (NcGRA7 and NcROP2Fam-1) necessary to accomplish new invasion waves in the neighbouring cells [32]. In fact, TgNTPase has been previously suggested to act as a timer for the $T$. gondii lytic cycle [42]. Since egress and invasion represent critical processes in which parasites are highly exposed to the host immune system, NcNTPase secretion could counteract the development of inflammatory responses to avoid tachyzoite clearance. Interestingly, it has been suggested that the TgNTPase may suppress the local host immune responses [37, 41-43], supporting this hypothesis.

In contrast to microneme proteins, whose secretion can be activated by calcium ionophores (A23187 and ethanol), T. gondii GRA proteins are constitutively released in a calcium-independent and a temperature-dependent mode [60-62]. Similarly, DTT exposure has recently been shown to specifically induce the secretion of the NcMIC2 protein [32]. This compound is an egress inducer that reduces the TgNTPase protein in vivo, and induces a rapid depletion of host cell ATP with a concurrent calcium flux [40, 57]. However, the effect of these treatments on $\mathrm{Tg} / \mathrm{NcNTPase}$ secretion had not been tested so far. Accordingly, we found that NcNTPase and NcGRA7 secretion occurs in tachyzoites undergoing egress regardless of the applied treatment (A23187, ethanol, or DTT at $37^{\circ} \mathrm{C}$ ). In addition, secretion was also found in tachyzoites maintained at $4{ }^{\circ} \mathrm{C}$, suggesting that the NcNTPase is constitutively secreted during the egress stage. Similar findings have been previously reported for the SnNTPase protein from S. neurona, which can be detected on secreted fractions without further treatment [38].

Intriguingly, both NcNTPase and NcGRA7 are phosphoproteins. This protein modification may indicate a common regulation mechanism necessary for their participation within the lytic cycle. We have recently employed the same Phos-Tag 1-DE approach to 
determine the phosphorylation state of the two rhoptry proteins NcROP40 and NcROP2Fam-1, and found that NcROP2Fam-1 protein was also phosphorylated [32]. Previous studies have also demonstrated the phosphorylation of TgROP2, TgROP4 and TgGRA7, but only in intracellular parasites [63-65]. Interestingly, phosphorylation of TgGRA6 has been shown to coincide with its association with the PVM [66, 67], and this could also be the case for NcNTPase and NcGRA7 proteins, which are also localized at the periphery of the PV. Nevertheless, TgGRA7 was shown to associate with the PVM independently of its phosphorylation status $[63,65,68]$. In fact, it was suggested that TgGRA7 phosphorylation might regulate the formation of complexes with other GRA proteins to facilitate secretion of transmembranedomain containing proteins [69].

\section{Conclusions}

In summary, we have unraveled, at least partially, the complex NcNTPase genome organization and demonstrate that three different loci and allele varition of the NcNTPase gene exist. However, the improvement of the current gene annotation within the Nc-Liv genome and the incorportation of new fully sequenced isolates would be highly desirable in order to clarify more accurately grade of gene expansion and polymorphism of the NcNTPase genes. The present work aimed to characterize the NcNTPase and NcGRA7 proteins through an integrative and descriptive approach in the context of the host-parasite relationship. NcNTPase and NcGRA7 are up-regulated, secreted and phosphorylated during egress and early invasion, which suggests that both are likely involved in these and the subsequent phases of the lytic cycle. Nevertheless, the specific role of the NcNTPase and NcGRA7 proteins remains to be elucidated. In this sense, reverse genetics would be useful to determine the NcNTPase and NcGRA7 function, and to assess the impact of NcNTPase expression in the pathogenicity displayed among isolates.

\section{Additional files}

Additional file 1: Clustal alignment of the genome NcNTPase and allele sequences from GeneBank database and this study. Primers for sequencing clones 1, 2, and 3 are displayed in the table below. (DOCX $46 \mathrm{~kb}$ )

Additional file 2: Clustal alignment of the up-stream regions of the NcNTPase 1, 2 and 3. Cis-acting elements (yellow) and the ORF of the NcNTPase genes (light blue) are displayed on the figure. Specific primers were designed to amplify the up-stream sequences of the NcNTPase 1, 2 and 3 as indicated in the table below. Forward primers were specific for the NCNTPase 1, 2 and 3 sequences, whilst reverse primer was common for all the copies. PCR amplification yielded a single fragment with the expected molecular weight (see figure below). (DOCX $53 \mathrm{~kb}$ )

\section{Acknowledgements}

We gratefully acknowledge Prof. Ma Teresa Miras Portugal's group from the Department of Biochemistry and Molecular Biology IV of the Complutense University (Madrid) for their confocal microscopy system. We also acknowledge Proteomics Facility UCM, a member of ProteoRed network, for carrying out the MS analyses, Dr. Diana Williams from the Liverpool School of Tropical Medicine (Liverpool, UK) for the N. caninum Nc-Liv isolate, and Dr. David Sibley from the Washington University School of Medicine (St. Louis, MO, USA) for the NCMIC2 antibody.

\section{Funding}

This work was supported by the AGL2010-22191/GAN and the AGL201344694-R grants from the Spanish Ministry of Economy and Competitiveness (M.I.N.E.C.O.) and the S2013/ABI2906 grant from the Community of Madrid. Iván Pastor-Fernández was supported by a fellowship from the Spanish Ministry of Education, Culture and Sports (M.E.C.D.), as part of the Program of Training of University Staff (F.P.U., grant number AP2009-0354). Paula García Lunar was supported by a fellowship from Complutense University of Madrid. Andrew Hemphill was supported by the Swiss National Science Foundation (grant No. 310030 146162). The funders had no role in study design, data collection and analysis, decision to publish, or preparation of the manuscript.

\section{Availability of data and material}

Not applicable.

\section{Authors' contributions}

IPF, JRC, GAG and LMOM conceived and designed the experiments. IPF, JRC, $P G L, V M H$ and $A H$ performed the experiments. IPF, JRC, GAG and LMOM analyzed the data. IPF, JRC, GAG, VMH, AH and LMOM wrote the paper. All authors read and approved the final version of the manuscript.

\section{Competing interests}

The authors declare that they have no competing interests.

\section{Consent for publication}

Not applicable.

\section{Ethics approval and consent to participate}

Antibody raising in rabbits was performed under the proceedings detailed by the current legislation at the time of the experiment (Spanish Royal Decree 1201/2005) and were approved by the Animal Research Committee of the Complutense University.

\section{Author details}

${ }^{1}$ SALUVET, Animal Health Department, Faculty of Veterinary Sciences, Complutense University of Madrid, Ciudad Universitaria s/n, 28040 Madrid, Spain. ${ }^{2}$ Institute of Parasitology, Vetsuisse Faculty, University of Berne, Länggass-Strasse 122, CH-3012 Berne, Switzerland.

Received: 27 January 2016 Accepted: 1 June 2016

Published online: 21 June 2016

\section{References}

1. Dubey JP, Schares G. Neosporosis in animals - The last five years. Vet Parasitol. 2011;180(1-2):90-108.

2. Hemphill A, Vonlaufen N, Naguleswaran A, Keller N, Riesen M, Guetg N, Srinivasan S, Alaeddine F. Tissue culture and explant approaches to studying and visualizing Neospora caninum and its interactions with the host cell. Microsc Microanal. 2004;10(5):602-20.

3. Hemphill A, Gottstein B, Kaufmann H. Adhesion and invasion of bovine endothelial cells by Neospora caninum. Parasitology. 1996;112(Pt 2):183-97.

4. Black MW, Boothroyd JC. Lytic cycle of Toxoplasma gondii. Microbiol Mol Biol Rev. 2000;64(3):607-23.

5. Sheiner L, Soldati-Favre D. Protein trafficking inside Toxoplasma gondii. Traffic. 2008;9(5):636-46.

6. Hemphill A, Debache K, Monney T, Schorer M, Guionaud C, Alaeddine F, Mueller N, Mueller J. Proteins mediating the Neospora caninum-host cell interaction as targets for vaccination. Front Biosci (Elite Ed). 2013;5:23-36.

7. Beyer TV, Svezhova NV, Radchenko Al, Sidorenko NV. Parasitophorous vacuole: morphofunctional diversity in different coccidian genera (a short insight into the problem). Cell Biol Int. 2002;26(10):861-71.

8. Mercier C, Dubremetz JF, Rauscher B, Lecordier L, Sibley LD, Cesbron-Delauw MF. Biogenesis of nanotubular network in Toxoplasma parasitophorous vacuole induced by parasite proteins. Mol Biol Cell. 2002;13(7):2397-409.

9. Mercier C, Cesbron-Delauw MF. Toxoplasma secretory granules: one population or more? Trends Parasitol. 2015;31(2):60-71. 
10. Aguado-Martínez A, Álvarez-García G, Schares G, Risco-Castillo V, FernándezGarcía A, Marugán-Hernández V, Ortega-Mora LM. Characterisation of NcGRA7 and NCSAG4 proteins: Immunolocalisation and their role in the host cell invasion by Neospora caninum tachyzoites. Acta Parasitol. 2010; 55(4):304-12.

11. Guionaud C, Hemphill A, Mevissen M, Alaeddine F. Molecular characterization of Neospora caninum MAG1, a dense granule protein secreted into the parasitophorous vacuole, and associated with the cyst wall and the cyst matrix. Parasitology. 2010;137(11):1605-19.

12. Reid AJ, Vermont SJ, Cotton JA, Harris D, Hill-Cawthorne GA, KonenWaisman S, Latham SM, Mourier T, Norton R, Quail MA, Sanders M, Shanmugam D, Sohal A, Wasmuth JD, Brunk B, Grigg ME, Howard JC, Parkinson J, Roos DS, Trees AJ, Berriman M, Pain A, Wastling JM. Comparative genomics of the apicomplexan parasites Toxoplasma gondii and Neospora caninum: Coccidia differing in host range and transmission strategy. PLoS Pathog. 2012;8(3):e1002567.

13. Asai T, Miura S, Sibley LD, Okabayashi H, Takeuchi T. Biochemical and molecular characterization of nucleoside triphosphate hydrolase isozymes from the parasitic protozoan Toxoplasma gondii. J Biol Chem. 1995;270(19):11391-7.

14. Rosowski EE, Lu D, Julien L, Rodda L, Gaiser RA, Jensen KD, Saeij JP. Strainspecific activation of the NF-kappaB pathway by GRA15, a novel Toxoplasma gondii dense granule protein. J Exp Med. 2011;208(1):195-212.

15. Braun L, Brenier-Pinchart MP, Yogavel M, Curt-Varesano A, Curt-Bertini RL, Hussain T, Kieffer-Jaquinod S, Coute Y, Pelloux H, Tardieux I, Sharma A, Belrhali H, Bougdour A, Hakimi MA. A Toxoplasma dense granule protein, GRA24, modulates the early immune response to infection by promoting a direct and sustained host p38 MAPK activation. J Exp Med. 2013;210(10):2071-86.

16. Shastri AJ, Marino ND, Franco M, Lodoen MB, Boothroyd JC. GRA25 is a novel virulence factor of Toxoplasma gondii and influences the host immune response. Infect Immun. 2014;82(6):2595-605.

17. Hermanns T, Muller UB, Konen-Waisman S, Howard JC, Steinfeldt T. The Toxoplasma gondii rhoptry protein ROP18 is an Irga6-specific kinase and regulated by the dense granule protein GRA7. Cell Microbiol. 2016;18(2):244-59.

18. Hemphill A, Gajendran N, Sonda S, Fuchs N, Gottstein B, Hentrich B, Jenkins M. Identification and characterisation of a dense granule-associated protein in Neospora caninum tachyzoites. Int J Parasitol. 1998;28(3):429-38.

19. Álvarez-García G, Pitarch A, Zaballos A, Fernández-García A, Gil C, GómezBautista M, Aguado-Martínez A, Ortega-Mora LM. The NcGRA7 gene encodes the immunodominant $17 \mathrm{kDa}$ antigen of Neospora caninum. Parasitology. 2007;134(Pt 1):41-50.

20. Asai T, Howe DK, Nakajima K, Nozaki T, Takeuchi T, Sibley LD. Neospora caninum: tachyzoites express a potent type-I nucleoside triphosphate hydrolase. Exp Parasitol. 1998;90(3):277-85.

21. Regidor-Cerrillo J, Álvarez-GarcíaGarcía G, Pastor-Fernández I, MarugánHernández V, Gómez-Bautista M, Ortega-Mora LM. Proteome expression changes among virulent and attenuated Neospora caninum isolates. J Proteomics. 2012;75(8):2306-18.

22. Bermudes D, Peck KR, Afifi MA, Beckers CJ, Joiner KA. Tandemly repeated genes encode nucleoside triphosphate hydrolase isoforms secreted into the parasitophorous vacuole of Toxoplasma gondii. J Biol Chem. 1994;269(46):29252-60.

23. Krug U, Zebisch M, Krauss M, Strater N. Structural insight into activation mechanism of Toxoplasma gondii nucleoside triphosphate diphosphohydrolases by disulfide reduction. J Biol Chem. 2012;287(5):3051-66.

24. Nakaar V, Samuel BU, Ngo EO, Joiner KA. Targeted reduction of nucleoside triphosphate hydrolase by antisense RNA inhibits Toxoplasma gondii proliferation. J Biol Chem. 1999;274(8):5083-7.

25. Olias P, Sibley LD. Functional analysis of Toxoplasma gondii Nucleoside Triphosphate Hydrolases I and II in acute mouse virulence and immune suppression. Infect Immun. 2016, In press.

26. Medina-Rivera A, Defrance M, Sand O, Herrmann C, Castro-Mondragon JA, Delerce J, Jaeger S, Blanchet C, Vincens P, Caron C, Staines DM, ContrerasMoreira B, Artufel M, Charbonnier-Khamvongsa L, Hernández C, Thieffry D, Thomas-Chollier M, van Helden J. RSAT 2015: regulatory sequence analysis tools. Nucleic Acids Res. 2015;43(W1):W50-6.

27. Barber JS, Holmdahl OJ, Owen MR, Guy F, Uggla A, Trees AJ. Characterization of the first European isolate of Neospora caninum (Dubey, Carpenter, Speer, Topper and Uggla). Parasitology. 1995;111(Pt 5):563-8.

28. Pérez-Zaballos FJ, Ortega-Mora LM, Álvarez-García G, Collantes-Fernández E, Navarro-Lozano V, García-Villada L, Costas E. Adaptation of Neospora caninum isolates to cell-culture changes: an argument in favor of its clonal population structure. J Parasitol. 2005;91(3):507-10.
29. Vonlaufen N, Muller N, Keller N, Naguleswaran A, Bohne W, McAllister MM, Bjorkman C, Muller E, Caldelari R, Hemphill A. Exogenous nitric oxide triggers Neospora caninum tachyzoite-to-bradyzoite stage conversion in murine epidermal keratinocyte cell cultures. Int J Parasitol. 2002;32(10):1253-65.

30. Pastor-Fernández I, Arranz-Solís D, Regidor-Cerrillo J, Álvarez-GarcíaGarcía G, Hemphill A, GarcíaGarcía-Culebras A, Cuevas-Martin C, Ortega-Mora LM. A vaccine formulation combining rhoptry proteins NcROP40 and NcROP2 improves pup survival in a pregnant mouse model of neosporosis. Vet Parasitol. 2015;207(3-4):203-15.

31. Risco-Castillo V, Fernández-García A, Zaballos A, Aguado-Martínez A, Hemphill A, Rodríguez-Bertos A, Álvarez-García G, Ortega-Mora LM. Molecular characterisation of BSR4, a novel bradyzoite-specific gene from Neospora caninum. Int J Parasitol. 2007;37(8-9):887-96.

32. Pastor-Fernández I, Regidor-Cerrillo J, Jimenez-Ruiz E, Álvarez-GarcíaGarcía G, Marugán-Hernández V, Hemphill A, Ortega-Mora LM. Characterization of the Neospora caninum NcROP40 and NCROP2Fam-1 rhoptry proteins during the tachyzoite lytic cycle. Parasitology. 2016;143(1):97-113.

33. Regidor-Cerrillo J, GarcíaGarcía-Lunar P, Pastor-Fernández I, ÁlvarezGarcíaGarcía G, Collantes-Fernández E, Gómez-Bautista M, Ortega-Mora LM. Neospora caninum tachyzoite immunome study reveals differences among three biologically different isolates. Vet Parasitol. 2015;212(3-4):92-9.

34. Lovett JL, Howe DK, Sibley LD. Molecular characterization of a thrombospondin-related anonymous protein homologue in Neospora caninum. Mol Biochem Parasitol. 2000;107(1):33-43.

35. Bjorkman C, Hemphill A. Characterization of Neospora caninum iscom antigens using monoclonal antibodies. Parasite Immunol. 1998;20(2):73-80.

36. Schmittgen TD, Livak KJ. Analyzing real-time PCR data by the comparative C(T) method. Nat Protoc. 2008;3(6):1101-8.

37. Sansom FM. The role of the NTPDase enzyme family in parasites: what do we know, and where to from here? Parasitology. 2012;139(8):963-80.

38. Zhang D, Gaji RY, Howe DK. Identification of a dithiol-dependent nucleoside triphosphate hydrolase in Sarcocystis neurona. Int J Parasitol. 2006;36(10-11): 1197-204.

39. Sibley LD, Niesman IR, Asai T, Takeuchi T. Toxoplasma gondii: secretion of a potent nucleoside triphosphate hydrolase into the parasitophorous vacuole. Exp Parasitol. 1994:79(3):301-11.

40. Silverman JA, Qi H, Riehl A, Beckers C, Nakaar V, Joiner KA. Induced activation of the Toxoplasma gondii nucleoside triphosphate hydrolase leads to depletion of host cell ATP levels and rapid exit of intracellular parasites from infected cells. J Biol Chem. 1998;273(20):12352-9.

41. Melo MB, Jensen KD, Saeij JP. Toxoplasma gondii effectors are master regulators of the inflammatory response. Trends Parasitol. 2011;27(11):487-95.

42. Santos RF, Possa MA, Bastos MS, Guedes PM, Almeida MR, Demarco R, VerjovskiAlmeida S, Bahia MT, Fietto JL. Influence of Ecto-nucleoside triphosphate diphosphohydrolase activity on Trypanosoma cruzi infectivity and virulence. PLoS Negl Trop Dis. 2009;3(3):e387.

43. Tonin AA, Da Silva AS, Ruchel JB, Rezer JF, Camillo G, Faccio L, Franca RT, Leal DB, Duarte MM, Vogel FF, de la Rue ML, Lopes ST. E-NTPDase and E-ADA activities in lymphocytes associated with the immune response of rats experimentally infected with Toxoplasma gondii. Exp Parasitol. 2013;135(2):325-30

44. Nakaar $V$, Bermudes D, Peck KR, Joiner KA. Upstream elements required for expression of nucleoside triphosphate hydrolase genes of Toxoplasma gondii. Mol Biochem Parasitol. 1998;92(2):229-39.

45. Mercier C, Lefebvre-Van Hende S, Garber GE, Lecordier L, Capron A, Cesbron-Delauw MF. Common cis-acting elements critical for the expression of several genes of Toxoplasma gondii. Mol Microbiol. 1996;21(2):421-8.

46. Gaji RY, Howe DK. The heptanucleotide motif GAGACGC is a key component of a cis-acting promoter element that is critical for SnSAG1 expression in Sarcocystis neurona. Mol Biochem Parasitol. 2009;166(1):85-8.

47. Hehl AB, Basso WU, Lippuner C, Ramakrishnan C, Okoniewski M, Walker RA, Grigg ME, Smith NC, Deplazes P. Asexual expansion of Toxoplasma gondii merozoites is distinct from tachyzoites and entails expression of nonoverlapping gene families to attach, invade, and replicate within feline enterocytes. BMC Genomics. 2015;16:66

48. Adomako-Ankomah Y, Wier GM, Borges AL, Wand HE, Boyle JP. Differential locus expansion distinguishes Toxoplasmatinae species and closely related strains of Toxoplasma gondii. MBio. 2014;5(1):e01003-13.

49. Lee EG, Kim JH, Shin YS, Shin GW, Suh MD, Kim DY, Kim YH, Kim GS, Jung TS. Establishment of a two-dimensional electrophoresis map for Neospora caninum tachyzoites by proteomics. Proteomics. 2003;3(12):2339-50. 
50. Shin YS, Shin GW, Kim YR, Lee EY, Yang HH, Palaksha KJ, Youn HJ, Kim JH, Kim DY, Marsh AE, Lakritz J, Jung TS. Comparison of proteome and antigenic proteome between two Neospora caninum isolates. Vet Parasitol. 2005;134(1-2):41-52.

51. Kikuchi T, Furuta T, Kojima S. Membrane localization and demonstration of isoforms of nucleoside triphosphate hydrolase from Toxoplasma gondii. Parasitology. 2001;122(Pt 1):15-23.

52. Le Roch KG, Johnson JR, Florens L, Zhou Y, Santrosyan A, Grainger M, Yan SF, Williamson KC, Holder AA, Carucci DJ, Yates JR 3rd. Global analysis of transcript and protein levels across the Plasmodium falciparum life cycle. Genome Res. 2004;14(11):2308-18.

53. Radke JR, Behnke MS, Mackey AJ, Radke JB, Roos DS, White MW. The transcriptome of Toxoplasma gondii. BMC Biol. 2005;3:26.

54. Gaji RY, Behnke MS, Lehmann MM, White MW, Carruthers VB. Cell cycle-dependent, intercellular transmission of Toxoplasma gondii is accompanied by marked changes in parasite gene expression. $\mathrm{Mol}$ Microbiol. 2011;79(1):192-204.

55. Lescault PJ, Thompson AB, Patil V, Lirussi D, Burton A, Margarit J, Bond J, Matrajt M. Genomic data reveal Toxoplasma gondii differentiation mutants are also impaired with respect to switching into a novel extracellular tachyzoite state. PLoS One. 2010;5(12):e14463.

56. Esposito M, Moores S, Naguleswaran A, Muller J, Hemphill A. Induction of tachyzoite egress from cells infected with the protozoan Neospora caninum by nitro- and bromo-thiazolides, a class of broad-spectrum anti-parasitic drugs 9. Int J Parasitol. 2007;37(10):1143-52.

57. Stommel EW, Cho ES, Steide JA, Seguin R, Barchowsky A, Schwartzman JD, Kasper LH. Identification and role of thiols in Toxoplasma gondii egress. Exp Biol Med. 2001;226(3):229-36.

58. Krug U, Totzauer R, Strater N. The crystal structure of Toxoplasma gondii nucleoside triphosphate diphosphohydrolase 1 represents a conformational intermediate in the reductive activation mechanism of the tetrameric enzyme. Proteins. 2013;81(7):1271-6.

59. Blackman MJ, Carruthers VB. Recent insights into apicomplexan parasite egress provide new views to a kill. Curr Opin Microbiol. 2013;16(4):459-64.

60. Chaturvedi S, Qi H, Coleman D, Rodríguez A, Hanson PI, Striepen B, Roos DS, Joiner KA. Constitutive calcium-independent release of Toxoplasma gondii dense granules occurs through the NSF/SNAP/SNARE/Rab machinery. J Biol Chem. 1999;274(4):2424-31.

61. Carruthers VB. Host cell invasion by the opportunistic pathogen Toxoplasma gondii. Acta Trop. 2002;81(2):111-22.

62. Phelps ED, Sweeney KR, Blader IJ. Toxoplasma gondii rhoptry discharge correlates with activation of the early growth response 2 host cell transcription factor. Infect Immun. 2008;76(10):4703-12.

63. Neudeck A, Stachelhaus S, Nischik N, Striepen B, Reichmann G, Fischer HG. Expression variance, biochemical and immunological properties of Toxoplasma gondii dense granule protein GRA7. Microbes Infect. 2002;4(6):581-90.

64. Carey $\mathrm{KL}$, Jongco AM, Kim K, Ward GE. The Toxoplasma gondii rhoptry protein ROP4 is secreted into the parasitophorous vacuole and becomes phosphorylated in infected cells. Eukaryot Cell. 2004;3(5):1320-30.

65. Dunn JD, Ravindran S, Kim SK, Boothroyd JC. The Toxoplasma gondii dense granule protein GRA7 is phosphorylated upon invasion and forms an unexpected association with the rhoptry proteins ROP2 and ROP4. Infect Immun. 2008;76(12):5853-61.

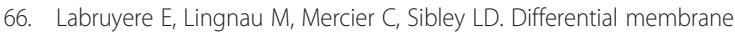
targeting of the secretory proteins GRA4 and GRA6 within the parasitophorous vacuole formed by Toxoplasma gondii. Mol Biochem Parasitol. 1999;102(2):311-24.

67. Mercier C, Adjogble KD, Daubener W, Delauw MF. Dense granules: are they key organelles to help understand the parasitophorous vacuole of all apicomplexa parasites? Int J Parasitol. 2005;35(8):829-49.

68. Coppens I, Dunn JD, Romano JD, Pypaert M, Zhang H, Boothroyd JC, Joiner KA. Toxoplasma gondii sequesters lysosomes from mammalian hosts in the vacuolar space. Cell. 2006;125(2):261-74.

69. Braun L, Travier L, Kieffer S, Musset K, Garin J, Mercier C, Cesbron-Delauw MF. Purification of Toxoplasma dense granule proteins reveals that they are in complexes throughout the secretory pathway. Mol Biochem Parasitol. 2008; 157(1):13-21.
70. Fernández-García A, Risco-Castillo V, Zaballos A, Álvarez-García G, OrtegaMora LM. Identification and molecular cloning of the Neospora caninum SAG4 gene specifically expressed at bradyzoite stage. Mol Biochem Parasitol. 2006;146(1):89-97.

71. Alaeddine F, Hemphill A, Debache K, Guionaud C. Molecular cloning and characterization of NCROP2Fam-1, a member of the ROP2 family of rhoptry proteins in Neospora caninum that is targeted by antibodies neutralizing host cell invasion in vitro. Parasitology. 2013;140(8):1033-50.

\section{Submit your next manuscript to BioMed Central and we will help you at every step:}

- We accept pre-submission inquiries

- Our selector tool helps you to find the most relevant journal

- We provide round the clock customer support

- Convenient online submission

- Thorough peer review

- Inclusion in PubMed and all major indexing services

- Maximum visibility for your research

Submit your manuscript at www.biomedcentral.com/submit 